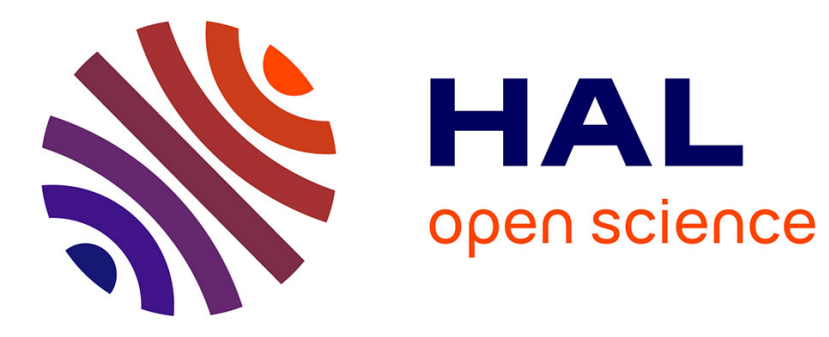

\title{
Contamination in bluetongue virus challenge experiments
}

Michael Echbaumer, Regula Wackerlin, Giovanni Vasini, Stéphan Zientara, Corinne Sailleau, Emmanuel Bréard, Martin Beer, Bernd Hoffmann

\section{- To cite this version:}

Michael Echbaumer, Regula Wackerlin, Giovanni Vasini, Stéphan Zientara, Corinne Sailleau, et al. Contamination in bluetongue virus challenge experiments. Vaccine, 2011, 29, pp.4299-4301. 10.1016/j.vaccine.2011.04.049 . hal-01228308

\section{HAL Id: hal-01228308 https://hal.science/hal-01228308}

Submitted on 12 Nov 2015

HAL is a multi-disciplinary open access archive for the deposit and dissemination of scientific research documents, whether they are published or not. The documents may come from teaching and research institutions in France or abroad, or from public or private research centers.
L'archive ouverte pluridisciplinaire HAL, est destinée au dépôt et à la diffusion de documents scientifiques de niveau recherche, publiés ou non, émanant des établissements d'enseignement et de recherche français ou étrangers, des laboratoires publics ou privés. 
Brief report

\title{
Contamination in bluetongue virus challenge experiments
}

\author{
Michael Eschbaumer ${ }^{\mathrm{a}, *}$, Regula Wäckerlin ${ }^{\mathrm{a}, 1}{ }$, Giovanni Savini $^{\mathrm{b}}$, Stéphan Zientara ${ }^{\mathrm{c}}$, Corinne Sailleau ${ }^{\mathrm{c}}$, \\ Emmanuel Bréard $^{c}$, Martin Beer ${ }^{\mathrm{a}}$, Bernd Hoffmann ${ }^{\mathrm{a}}$ \\ a Institute of Diagnostic Virology, Friedrich-Loeffler-Institut (FLI), Südufer 10, 17493 Greifswald-Insel Riems, Germany \\ ${ }^{\mathrm{b}}$ Istituto G. Caporale, Teramo, Italy \\ ' UMR 1161 Virologie, Agence nationale de sécurité sanitaire de l'alimentation, de l'environnement et du travail (ANSES), Laboratoire de Santé Animale, Maisons-Alfort, France
}

\section{A R T I C L E I N F O}

\section{Article history:}

Received 18 February 2011

Received in revised form 9 April 2011

Accepted 18 April 2011

Available online 8 May 2011

\section{Keywords:}

Bluetongue

Vaccination

Challenge

Contamination

Serotype-specific RT-PCR

\begin{abstract}
A B S T R A C T
Five cattle and five sheep that had never been exposed to bluetongue virus (BTV), as well as ten animals that had been experimentally infected with BTV-8, were inoculated with BTV-1. Previous exposure to BTV-8 did not prevent a second infection with another serotype.

After the experiment, the BTV-1 preparation was found to be contaminated with BTV-15. The inoculum and blood samples taken during the experiment were analysed by serotype-specific real-time RT-PCR. There was 100-fold less BTV-15 than BTV-1 in the inoculum. Unexpectedly, BTV-15 dominated the infection in cattle that had previously been exposed to BTV-8. In sheep of both groups, on the other hand, BTV-1 prevailed over the contaminant.

Regardless of the outcome, the incident demonstrates the need for a thorough contamination screening of virus preparations. For this purpose, two type-specific RT-PCR primer sets for each of the 24 established BTV serotypes as well as Toggenburg Orbivirus were designed.
\end{abstract}

(c) 2011 Elsevier Ltd. All rights reserved.
There are at least 24 serotypes of Bluetongue virus (BTV), an arthropod-borne reovirus that affects domestic and wild ruminants worldwide. In many research laboratories, different strains and serotypes of BTV as well as related viruses are handled at the same time. Despite best efforts, contamination does occur and can have far-reaching consequences.

In the present study, six Holstein Friesian cattle and four German Blackhead Mutton sheep had been experimentally infected with BTV-8 (isolated in Germany in 2007). Six weeks later, they were challenged with a French isolate of BTV-1, kindly provided by ANSES. To investigate the cross-protective influence of the previous exposure to BTV-8, five BTV-naïve cattle and sheep were also inoculated with the same BTV-1 preparation at the same time. All animals were subcutaneously injected with Vero cell culture supernatant that contained $10^{6.3} \mathrm{TCID}_{50}$ of BTV. Since the BTV-1 isolate had originally been intended for PCR validation only, it had not undergone the usual checks for a challenge inoculum at the sending laboratory. In fact, ANSES had not certified it as pure. For the experiment, the received material was passaged once at the FLI. Real-time RT-PCR analysis [1] of the passaged material confirmed

\footnotetext{
* Corresponding author. Tel.: +49 383517 1280; fax: +49 3835171275 .

E-mail address: michael.eschbaumer@fli.bund.de (M. Eschbaumer).

1 Present address: Department of Ecosystem and Public Health, Faculty of Veterinary Medicine, University of Calgary, Calgary, AB, Canada.
}

Table 1

BTV-15 specific RT-PCR and real-time RT-PCR assays used for sample analysis.

\begin{tabular}{|c|c|}
\hline \multicolumn{2}{|l|}{ RT-PCR primers } \\
\hline BTV15-192F & 5' GTGTTGGACTGAAATATCGTCC 3' \\
\hline BTV15-604R & 5' CAATATGTAACCTACCTCCTTGC $3^{\prime}$ \\
\hline \multicolumn{2}{|c|}{ Real-time RT-PCR primers and probe } \\
\hline BTV15-VP2-978F & 5' TGTTCCGCACGGAGAACAGCG 3' \\
\hline BTV15-VP2-1079R & 5' CGGTCGCTGCGATTATTAGAGGTGC 3' \\
\hline BTV15-VP2-1045FAMas & 5' 6FAM-CTGCCTCTGCGTTCTGCCACTGCCT-BHQ1 3' \\
\hline
\end{tabular}

that it contained a large amount of BTV-1, but other serotypes were not tested for. It was later revealed that the BTV-1 isolate had been contaminated with BTV-15.

This contamination was only discovered when samples from the animal experiment were sent to the Istituto G. Caporale for serum neutralization tests. After neutralizing antibodies against BTV-15 had been found in serum samples, blood from the animals and the supernatant used for infection were examined by a serotypespecific RT-PCR amplifying a 413 bp fragment of BTV-15 genome segment 2 (see Table 1 ). Since these were also positive, the inoculum and all samples from the animal experiment were re-tested using a modified CY5-labeled BTV-1 assay [1] and a newly designed BTV-15 assay (see Table 1) in a single-tube duplex real-time RT-PCR. Serial dilutions of BTV-1 and BTV-15 RNA preparations whose copy numbers had been determined by an externally calibrated pan-BTV S5 assay [2] were used for absolute quantification. 

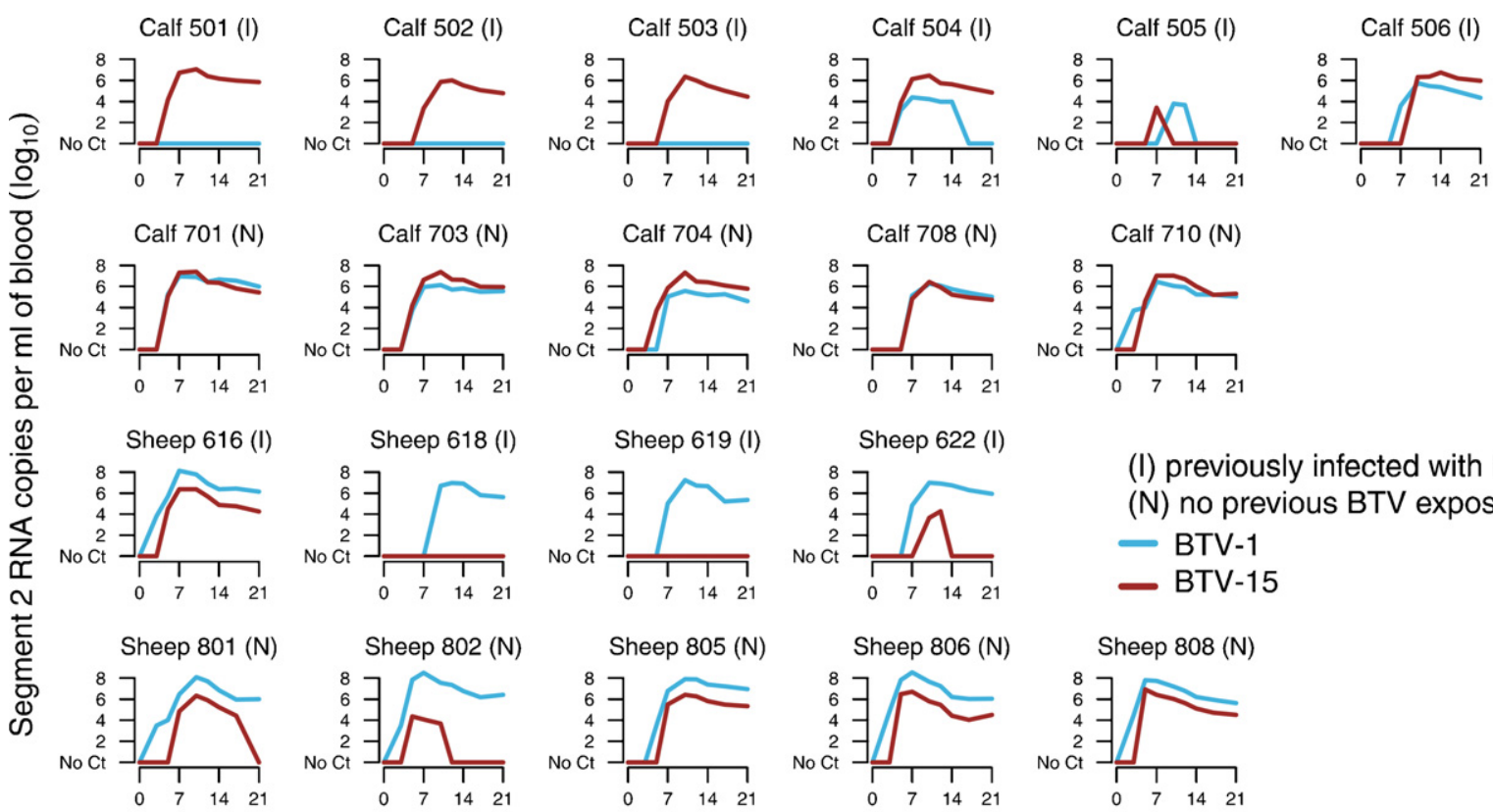

\section{(I) previously infected with BTV-8 (N) no previous BTV exposure

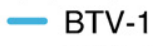 \\ BTV-15}
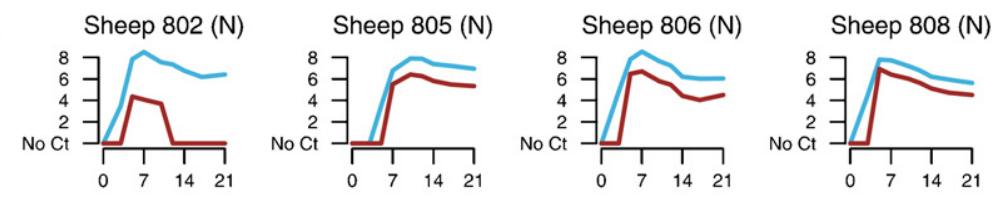

Days after challenge infection

Fig. 1. Results of serotype-specific real-time RT-PCR analysis of blood samples taken after challenge infection.

The VP2 gene sequence of the contaminant was obtained and deposited in GenBank (accession number JF343006). BLAST analysis $^{2}$ revealed only $96 \%$ identity to the VP2 gene of the South African reference strain "RSArrrr/15", the only available BTV-15 VP2 gene sequence in the database. The BTV-1 strain used in this study had originally been isolated in France from a sheep with clinical signs of bluetongue. There is no indication that BTV-15 has ever circulated in Europe. An Israeli strain of BTV-15, however, had been handled at the sending laboratory at the same time as the BTV-1 isolate. This is suspected as the origin of the contamination, but no further attempt was made to confirm that.

In the real-time RT-PCR, the inoculum was strongly positive for BTV-1 RNA with a mean $C_{\mathrm{t}}$ value of $17.1\left(3.4 \times 10^{9}\right.$ segment 2 RNA copies per $\mathrm{ml}$ ), but also contained an about 100 -fold lower amount of BTV-15 $\left(C_{\mathrm{t}} 24.6 ; 3.6 \times 10^{7}\right.$ copies per $\left.\mathrm{ml}\right)$. Surprisingly, this difference was not uniformly reflected in the course of infection observed in the experiment.

The outcome was very different between the two host species (see Fig. 1). High amounts of BTV-1 RNA were detected in all sheep, regardless of their BTV exposure history. Two of the four previously BTV-8 infected sheep did not show any BTV-15 replication at all, and it was much reduced in a third. In naïve sheep, BTV-15 replication on average was reduced 100 -fold compared to BTV-1.

In three of the six cattle previously infected with BTV-8, on the other hand, no BTV-1 replication was detected at all, and it was about 100 -fold reduced in a fourth. Interestingly, previously infected cattle that were negative for BTV-1 were highly positive for BTV-15. Finally, in samples from naïve cattle, BTV-1 and BTV-15 RNA were detected in roughly equal amounts.

In summary, even though there was over 100-fold less BTV-15 in the inoculum, this serotype dominated the infection in cattle that had previously been exposed to BTV-8. In sheep of both groups,

2 NCBI Basic Local Alignment Search Tool, http://blast.ncbi.nlm.nih.gov. on the other hand, BTV-1 prevailed over the contaminant. A BTV infection with a single serotype generally does not induce immunity to other serotypes [3], and previous BTV-8 exposure did not prevent infection with another BTV serotype in either species in this experiment.

The observed differences in replication suggest that the contaminating strain of BTV-15 is particularly well adapted to cattle, considering it easily made up for the over 100-fold lower inoculated dose. It is unclear whether the dominance of BTV-1 in sheep is simply due to interference between the viruses (where the lower dose could place BTV-15 at a competitive disadvantage), or if BTV-1 in turn is better suited to replication in sheep. Jeggo et al. have previously proposed a mechanism for interference based on cross-reactive cytotoxic T-lymphocytes [4], and another study of mixed BTV infection of sheep has also reported differences in growth behavior between virus strains [5]. It is well established that the clinical manifestation of BTV infection varies between host species as well as virus strains [6], but little is known about the species preference of individual BTV strains, if indeed there is any.

In any case, this experiment as well as a similar incident recently reported by Bréard et al. [7] should serve as a reminder to everybody to always screen their virus preparations carefully. For this purpose, we have prepared two segment 2 primer pairs specific for each of the 24 established BTV serotypes and Toggenburg Orbivirus [8] (see Table 2). Fragment sizes have been reduced compared to previously published primer sets [9] to increase sensitivity; still, owing to the small sample volumes used for nucleic acid extraction, RT-PCR is not always sufficiently sensitive to detect minute contaminations. As the challenge experiment of Bréard et al. aptly demonstrates, the inoculation of animals vaccinated against the predominant serotype is the "gold standard" for contamination screening. Recently, Calvo-Pinilla et al. have shown that vaccination with inactivated vaccines can protect mice against fatal BTV infection [10], providing a small animal model that can be very useful in this context. Our experiment in turn proves the value of a 
Table 2

Degenerate segment 2 RT-PCR primers for all established BTV serotypes and Toggenburg Orbivirus.

\begin{tabular}{|c|c|c|c|c|}
\hline Forward primer & Sequence $5^{\prime}-3^{\prime}$ & Reverse primer & Sequence $5^{\prime}-3^{\prime}$ & Fragment sizes (bp) \\
\hline BTV1-220F & ATGGWWTTGTVBTRCCGCGAGT & BTV1-818R & YGTATCCAYCTATTRCATATCTC & \multirow{2}{*}{ 599, 480, 409, 291} \\
\hline BTV1-339F & ATGATGAAAGATTCRATGGACGC & BTV1-629R & CGATCTCTCCTKTCAGCGTG & \\
\hline BTV2-330F & GTWCAGTGGATGATTAARGATAG & BTV2-916R & TCAACSGGTTCCGCTTCTTG & \multirow{2}{*}{$587,540,383,336$} \\
\hline BTV2-377F & ATCGATTGAYGARGAACATAGCC & BTV2-712R & GTATACGCTTCRTCRCCCATTTG & \\
\hline BTV3-170F & ATGTAGCGCAGCAAGGCATCA & BTV3-711R & AGCGTTATCTCCTAACTGCATAC & \multirow{2}{*}{$542,483,467,408$} \\
\hline BTV3-229F & GAGGTTTTACCTCGCATCTTAGA & BTV3-636R & TTCCGTTGACAACCGTTCAGA & \\
\hline BTV4-194F & AGCGCGCTTAACTATAAACCAAC & BTV4-840R & ATCCGAGTTCTATCATATGACGC & \multirow{2}{*}{$647,589,560,502$} \\
\hline BTV4-281F & AAGTCGGTTAAGAACGCACGC & BTV4-782R & TAATYTCYССYСТTATTATATCTGG & \\
\hline BTV5-280F & AAAGYTTMAACACRAAYAGTGGTGT & BTV5-818R & ACGTTTCCACGCCTCRCGTAT & \multirow{2}{*}{$539,500,414,375$} \\
\hline BTV5-319F & ATCAYAAATGGATGGARTGGATG & BTV5-693R & TGTCAACYCTTGCYCTTCTCC & \\
\hline BTV6-168F & GATGTTCCGATTCGTGAAGCG & BTV6-745R & ACTTTGCCCTGCACACGCA & \multirow{2}{*}{$578,540,538,500$} \\
\hline BTV6-206F & AAGGAATGATGGTCACGTGCTA & BTV6-705R & TCTTCTTATATGGCTCATCTCCTA & \\
\hline BTV7-186F & AGCGATGCAGGATGCTAATTC & BTV7-786R & САТСТСТТСТСТААССАТАТССG & \multirow{2}{*}{$601,540,481,420$} \\
\hline BTV7-306F & TATAGAGAAGATGACTAATCAAACC & BTV7-725R & AACATGCGGTTGTACTGGTCT & \\
\hline BTV8-186F & GATGAACATATACGTGATGCGATTA & BTV8-733R & ААСССТTСТTTСААСТTCTGGTA & \multirow{2}{*}{$548,463,439,354$} \\
\hline BTV8-295F & TTRTTTTGAATGATGGTCATAGCGA & BTV8-648R & AATCACTCGTTGATGCACGTTC & \\
\hline BTV9-163F & CAATWGATGTGCCWGATGGTGA & BTV9-612R & AATGYACTCKTARWACGTACGTATC & \multirow{2}{*}{$450,394,291,235$} \\
\hline BTV9-322F & ATAARTGGATGGARTGGATGCT & BTV9-556R & TTATATAACCCATTATTTATYAGATGGTT & \\
\hline BTV10-183F & AATCRGATATGATCGACGTACC & BTV10-739R & TTCGTACGGCTGCCCTCTATA & \multirow{2}{*}{$557,515,485,443$} \\
\hline BTV10-255F & GWGTGGTYGTGCCGAGATTG & BTV10-697R & CAGCTGTATCCATCTCTGCGT & \\
\hline BTV11-224F & GAYGGGATCGTGGTTCCTAG & BTV11-796R & CWCRTTTAGCCGCGCGATATC & \multirow{2}{*}{$573,533,463,423$} \\
\hline BTV11-264F & GAGCKTATGACGATAGAAAAGC & BTV11-686R & TTCGCGTSCCTCTCACTAAG & \\
\hline BTV12-218F & AATTTATCTCATGTTATAACACCGTC & BTV12-670R & CCCATTTACGATGAGTTGATCTC & \multirow{2}{*}{$453,390,382,319$} \\
\hline BTV12-281F & CACAAAATTGCGTTAGACAAACG & BTV12-599R & TCAAAGTGTATCCCGCGGTC & \\
\hline BTV13-177F & GGTTCARCCAATAAGAGATGCAAT & BTV13-835R & GCTCATAATTTCCСTGTATCCAT & \multirow{2}{*}{$658,550,452,343$} \\
\hline BTV13-286F & ATGATGAARAGAGATGGCGTAGA & BTV13-628R & TCCTCCGCTCAGAGTTAACG & \\
\hline BTV14-169F & ATGTGCCGATACGTGATGCC & BTV14-696R & AAGCATCATCACCCAGTACCA & \multirow{2}{*}{$528,457,439,368$} \\
\hline BTV14-258F & TATGACCGGAGGAAATATCACAA & BTV14-625R & GCCTCATCAGTTGTGGCTCT & \\
\hline BTV15-192F & GTGTTGGACTGAAATATCGTCC & BTV15-670R & CACTCGCAACTCCTGTCTTTG & \multirow{2}{*}{$479,413,411,345$} \\
\hline BTV15-260F & ATAAGAGCATACGATCATAAACATC & BTV15-604R & CAATATGTAACСТAССТССТTGC & \\
\hline BTV16-187F & ATCAGAGAGGCAATAGAATACAAAC & BTV16-660R & ATGTTCGCCAATCCTAAATTCATC & \multirow{2}{*}{$474,433,413,372$} \\
\hline BTV16-248F & AGATATGTCTATTGCGTGTTACGA & BTV16-619R & CACCAATCACTATTAAATCATACGTC & \\
\hline BTV17-227F & GGRATCGTTGTACCTAGATTACT & BTV17-689R & CTATTCGCGTTCCTCTAGTCAA & \multirow{2}{*}{$463,386,355,278$} \\
\hline BTV17-304F & GATAGAGTTCATGACGAACGCTA & BTV17-581R & TAGCACCTTGCAACGCGTG & \\
\hline BTV18-199F & TATACAAACCAGTCAGTAACGATG & BTV18-669R & TCCGATTCAACTCGAGCGTC & \multirow{2}{*}{$471,416,385,329$} \\
\hline BTV18-254F & TTTAAGAGCATTTGATGATAGGAAG & BTV18-583R & AATATATAAGCGGCCTCCTGC & \\
\hline BTV19-180F & TGATATACCAATACAGGATGCTAC & BTV19-683R & CCACGCCGCATACTAGTTAG & \multirow{2}{*}{$504,424,419,339$} \\
\hline BTV19-265F & GCTGCTTACGATACGCGGAA & BTV19-603R & CTTCTGCGTAGGCTTGAGCA & \\
\hline BTV20-204F & ACTATAAACCTGTGAGGAATGATG & BTV20-659R & ATTTCTGGGACCCGATTGGATA & \multirow{2}{*}{$456,390,353,287$} \\
\hline BTV20-270F & ACGACGATAGGAAGTCAACGAA & BTV20-556R & GTGAAACATCTCAACAGCTGTC & \\
\hline BTV21-181F & GCGAAGCTCTGAACTACTTAC & BTV21-694R & GCATCATCTCCTAGAACTATTCG & \multirow{2}{*}{$514,445,405,336$} \\
\hline BTV21-250F & TGAGCGGGTACGATAGACGA & BTV21-585R & CGAGCGTGGGTTTCAGAATG & \\
\hline BTV22-156F & AAATTAAAGGCGTATGTGTGCGG & BTV22-641R & TTTCACGAACCTCTGTACGCA & \\
\hline BTV22-220F & TTTATCACATGTTATCACGCCATC & BTV22-586R & TGCTGTCTTCGATACCTGGAA & $486,431,422,367$ \\
\hline BTV23-202F & CTAARCCTGTTAGCAATGACG & BTV23-819R & GTGGCYGCTGTTAATCCATCT & \\
\hline BTV23-287F & AACGAGTGGAGGTCAGAGTG & BTV23-658R & TCTATCGTCCTTCCGTTAWAAGT & $618,533,457,372$ \\
\hline BTV24-195F & GACGCACTCAGTTACAGACC & BTV24-704R & AGGTTCTCCTCTACTTCCTATC & \\
\hline BTV24-271F & ATGATCGGAAGGCAACGAAGA & BTV24-643R & GGATAACTCTCACCCGTATTCT & $510,449,434,373$ \\
\hline BTV25-193F & CCTTCGAGGAATGATGGGATA & BTV25-698R & AACATATCGTAAGCGTTGCCG & \\
\hline BTV25-256F & AAGAGACGGTCGATGAAGGATA & BTV25-624R & GTCATATCTCTGTCGTACGTC & $506,443,432,369$ \\
\hline
\end{tabular}

thorough serological analysis of samples beyond the serotypes one expects to be there.

\section{Acknowledgements}

Dr. Michael Eschbaumer was supported by the EU Network of Excellence for Epizootic Disease Diagnosis and Control (EPIZONE, contract no. FOOD-CT-2006-016236) as well as the EU Seventh Framework Programme project ORBIVAC (Ref. 245266).

\section{References}

[1] Hoffmann B, Eschbaumer M, Beer M. Real-time quantitative reverse transcription-PCR assays specifically detecting bluetongue virus serotypes 1 , 6, and 8. J Clin Microbiol 2009;47(September (9)):2992-4.

[2] Toussaint JF, Sailleau C, Bréard E, Zientara S, De Clercq K. Bluetongue virus detection by two real-time RT-qPCRs targeting two different genomic segments. J Virol Methods 2007;140(March (1-2)):115-23.

[3] Jeggo MH, Gumm ID, Taylor WP. Clinical and serological response of sheep to serial challenge with different bluetongue virus types. Res Vet Sci 1983;34(March (2)):205-11.
[4] Jeggo MH, Wardley RC, Taylor WP. Clinical and serological outcome following the simultaneous inoculation of three bluetongue virus types into sheep. Res Vet Sci 1984;37(November (3)):368-70.

[5] Samal SK, Livingston Jr CW, McConnell S, Ramig RF. Analysis of mixed infection of sheep with bluetongue virus serotypes 10 and 17: evidence for genetic reassortment in the vertebrate host. J Virol 1987;61(April (4)):1086-91.

[6] MacLachlan NJ, Drew CP, Darpel KE, Worwa G. The pathology and pathogenesis of bluetongue. J Comp Pathol 2009;141(July (1)):1-16.

[7] Bréard E, Belbis G, Hamers C, Moulin V, Lilin T, Moreau F, et al. Evaluation of humoral response and protective efficacy of two inactivated vaccines against bluetongue virus after vaccination of goats. Vaccine 2011;29(March (13)):2495-502.

[8] Hofmann MA, Renzullo S, Mader M, Chaignat V, Worwa G, Thuer B. Genetic characterization of toggenburg orbivirus, a new bluetongue virus, from goats, Switzerland. Emerg Infect Dis 2008;14(December (12)): 1855-61.

[9] Mertens PP, Maan NS, Prasad G, Samuel AR, Shaw AE, Potgieter AC, et al. Design of primers and use of RT-PCR assays for typing European bluetongue virus isolates: differentiation of field and vaccine strains. J Gen Virol 2007;88(October (Pt 10)):2811-23.

[10] Calvo-Pinilla E, Rodríguez-Calvo T, Anguita J, Sevilla N, Ortego J. Establishment of a bluetongue virus infection model in mice that are deficient in the alpha/beta interferon receptor. PLoS One 2009;4(4):e5171. 